\title{
A relevância das práticas de leitura e escrita na formação do sujeito inserido na educação de jovens e adultos: um estudo de caso
}

The relevance of reading and writing practices in the formation of the subject inserted in the young and adults education: a case study

\author{
Cristiane Schmidt ${ }^{1}(\mathbb{D})$, Maria Carolina Brustolin ${ }^{2}(\mathbb{D})$
}

${ }^{1}$ Universidade Federal do Pará (UFPA), Brasil, Doutora em Letras (Unioeste), Professora Adjunta do Instituto de Letras e Comunicação (UFPA) e do Programa de Pós-Graduação em Linguística (Unemat), e-mail: schmidt@ufpa.br

${ }^{2}$ Rede Pública de Ensino (Cascavel/PR), Brasil, Licenciada em Pedagogia (Unioeste), Pedagoga da Rede Pública de Cascavel/PR, e-mail: ca-rolina-brustolin@ hotmail.com

\begin{abstract}
RESUMO
A formação permanente do ser humano tem sido tema de vários debates na área da educação, visando sua interação na sociedade marcada pela diversidade sociocultural e linguística e pelo aprendizado permanente, independente da sua idade cronológica. Considerando isso, a questão orientadora deste estudo busca investigar como estão sendo abordadas na modalidade da Educação de Jovens e Adultos (EJA) as práticas de leitura e escrita. Ao mesmo tempo, o artigo tem por finalidade compreender a relevância dessas práticas na formação desses alunos na perspectiva da Educação Permanente. Como referencial teórico, destacam-se as pesquisas de Freire (1982;1983), Antunes (2010) e Soares (2001; 2003). Para tanto, a metodologia vale-se da abordagem qualitativa, com base num estudo de caso, especificamente, as análises voltam-se para uma escola localizada no município de Cascavel, situado na região oeste paranaense. Os resultados apontam que as práticas de leitura e escrita assumem uma dimensão de grande importância na formação e inserção destes sujeitos na sociedade.
\end{abstract}

Palavras-chave: Práticas de leitura e escrita. Educação de Jovens e Adultos. Estudo de caso.

\begin{abstract}
The permanent formation of the human being has been an issue of several debates in the field of education aiming at one's interaction with society, which is characterized by sociocultural and linguistic diversity and by the permanent learning, no matter the age group. Considering that, the main idea of this study is to investigate how the reading and writing practices are being approached in the modality of Young and Adults Education. At the same time, the article has as its aim to understand the relevance of these practices in the formation of these students in the perspective of Permanent Education. As theoretical background, we highlight the researches of Freire (1982,1983), Antunes (2010) and Soares $(2001,2003)$. For that, the methodology is built on the qualitative approach based on a case study and the analysis are specifically carried out in the district of Cascavel, situated in the West region of the state of Paraná. The results point out that the reading and writing practices assume a dimension of great importance in the formation and insertion of these subjects in society.
\end{abstract}

Keywords: Reading and writing practices. Young and Adults Education. Study case. 


\section{INTRODUÇÃO}

No contexto contemporâneo, as necessidades de usos da linguagem permeando as interações socioculturais em contextos reais e/ou virtuais são cada vez mais constantes. Nesse sentido, dentre as habilidades comunicativas, a leitura tem importância e papel de destaque, já que por meio dela, o homem se comunica, dialoga, expõe ideias, pensamentos, opiniões. Além disso, a leitura é entendida aqui como uma possibilidade de conhecimento das diversas áreas do saber, assim como requer a participação de autor e leitor, visando a construção de significados.

Com base nisso, destaca-se a inserção crescente de adultos e, até mesmo pessoas em idade avançada, ao processo formal de escolarização, os quais são direcionados por diversos fatores e necessidades do mundo contemporâneo, numa perspectiva de uma educação para a vida toda.

A partir dessa delineação inicial, este estudo visa compreender a relevância das práticas de leitura e escrita na modalidade da Educação de Jovens e Adultos (EJA), da Escola Municipal Francisco Vaz de Lima do Município de Cascavel, no Estado do Paraná.

Dentre as inquietações que motivaram a presente investigação, pode-se mencionar alguns questionamentos:

(i) $\mathrm{O}$ interesse pela leitura influencia na escolha dos alunos a procurarem uma instituição e a EJA?

(ii) E ao serem inseridos no ambiente escolar, como esses alunos enfrentam os desafios em relação às práticas da leitura e da escrita? E o que essas práticas representam para esses sujeitos?

(iii) Qual a relação do indivíduo com o contexto em que está inserido e as contribuições individuais e sociais para a continuidade do processo de alfabetização?

A partir do exposto, depreende-se que a temática voltada à leitura e à escrita como práticas indissociáveis, façam parte da sociedade do conhecimento e sejam necessárias, sobretudo com a inserção das novas tecnologias, de forma a viabilizar a comunicação linguística e a interação entre pessoas inseridas em processos educacionais.

Revista Expectativa, Toledo/PR, v. 20, n. 2, p. 164-182, abr./jun., 2021. 


\section{REFERENCIAL TEÓRICO}

\subsection{CONCEPÇÕES DE PRÁTICAS DE LEITURA E ESCRITA}

No entendimento de Silva (1999), existem várias concepções de leitura, das quais muitas são tidas como noções redutoras, uma vez que desprezam elementos fundamentais, vindo a diminuir a sua complexidade processual. Dentre essas definições redutoras, Silva (1999) menciona, por exemplo, que ler é traduzir a escrita em fala; ler significa decodificar mensagens; ler traduz-se a identificar a ideia central de um determinado texto; ler é seguir os passos da lição do livro didático e, ainda, ler é apreciar os clássicos.

Concorda-se com o posicionamento desse autor, já que a leitura não pode ficar restrita as tais concepções, pois elas limitam a formação linguística e discursiva de leitores, assim como dificultam o acesso as múltiplas facetas da leitura e tampouco auxiliam na interação entre autor, texto e leitor.

O processo da leitura e da escrita, segundo Antunes (2010), são processos eminentemente interativos, por isso não tem sentido escrever quando não se está procurando agir com o outro, trocar ideias, informações, sob algum pretexto. Assim como são atividades contextualizadas, situadas em algum momento, espaço e evento cultural.

E, dentre outras características, essas práticas são atividades que se manifestam em gêneros particulares de texto, uma vez que existem gêneros textuais diversos e com aspectos tipológicos distintos. Como em outras áreas sociais, os usuários da língua estão sujeitos aos esquemas convencionais, definidos institucionalmente e legitimados pela própria recorrência.

A leitura, sobretudo, pode ser concebida como um processo em que o leitor realiza um trabalho ativo de construção do significado do texto. Também na leitura participa-se do processo sócio-histórico de produção se sentidos, sendo que isso se faz de um lugar e tempo determinado (contexto). Como atividade dinâmica e interativa entre autor, texto e leitor na interpretação e compreensão de sentidos, ao ler está-se produzindo ou recriando sentidos.

No entendimento de Freire (1982), a formação do leitor se inicia antes mesmo do ambiente escolar mediante a leitura de mundo, no caso, da realidade linguística, sócio-histórica e cultural. No entanto, é comumente na escola e por meio dela que a maioria das pessoas tem acesso ao mundo letrado.

Revista Expectativa, Toledo/PR, v. 20, n. 2, p. 164-182, abr./jun., 2021. 
Conforme as pesquisas de Magda Soares $(2001 ; 2003)$, a alfabetização ${ }^{1}$ é caracterizada pela aquisição de códigos para a leitura e a escrita, representando um estado (alfabetizado ou não alfabetizado/analfabeto). Esse processo revela-se, também, todas as vezes que se recorre a um dicionário, por exemplo, para identificar o significado e os usos de determinada palavra; assim a alfabetização volta-se para o indivíduo.

Já, o verbete letramento é recente às Ciências da Educação e da Linguística, vindo a designar o processo de como as pessoas se relacionam com um mundo baseado na cultura da escrita. Dessa forma, uma pessoa pode não saber ler nem escrever, mas ser letrada, pois ser letrado implica usar socialmente a leitura e a escrita e responder às demandas sociais dessas práticas. Dessa forma, letramento pode ser definido como o estado ou a condição que adquire um grupo social ou um indivíduo como consequência de ter se apropriado da leitura e da escrita (SOARES, 2001).

No que tange às origens dos Estudos de Letramento, destaca-se o pesquisador britânico Brian Street, ao realizar suas pesquisas na interface das áreas da Linguística, da Educação e da Antropologia. Letramento, segundo Brian Street em sua obra Letramento em teoria e prática (1984), designa práticas sociais e concepções de leitura e escrita adquiridas por um indivíduo ou grupo social, esteja ele alfabetizado ou não.

Nesse sentido, a pessoa que detém práticas de letramento ${ }^{2}$ consegue interagir em distintos ambientes de usos da língua, pois atende outras demandas sociais da leitura e da escrita. Por este motivo consegue fazer escritas de sua própria autoria, produzir gêneros textuais como cartas, bilhetes e lista de gastos pessoais, ao contrário da pessoa alfabetizada, que lê apenas textos que circulam na esfera escolar.

Depreende-se que as práticas da leitura e escrita sejam de suma importância para a formação do sujeito crítico, visando condições de interagir de forma proficiente nos diversos contextos linguísticos e socioculturais. Ainda, para que a pessoa possa ler e elaborar suas

\footnotetext{
${ }^{1}$ Segundo Ângela Kleiman (1995), o conceito de letramento foi usado pela primeira vez, no Brasil, por Mary Kato em seu livro "No mundo da escrita: uma perspectiva psicolinguística" (1986), numa tentativa de separar os estudos sobre o impacto social da escrita dos estudos sobre a alfabetização, cujas conotações escolares destacam as competências individuais no uso e na prática da escrita.

${ }^{2}$ Para aprofundar a temática constam os Novos Estudo de Letramento. STREET, Brian. Eventos de letramento e práticas de letramento: teoria e prática nos novos estudos de letramento. In: MAGALHÃES, I. (Org.). Discursos e práticas de letramento: pesquisa etnográfica e formação de professores. Campinas, SP: Mercado de Letras, 2012.
}

Revista Expectativa, Toledo/PR, v. 20, n. 2, p. 164-182, abr./jun., 2021. 
próprias conclusões sobre o texto e o contexto, ou até mesmo nas leituras mais simples, poder ter a satisfação de apenas ler e se sentir livre.

Para Freire (1982), letramento tanto poderia ser um meio para a libertação do sujeito, o que se verifica, por exemplo, no fato de uma pessoa letrada registrar e assinar o seu próprio nome, elaborar uma lista de supermercado, ou ainda auxiliar seus filhos na lição de casa. Assim, a pessoa letrada teria um meio para tomar consciência da sua realidade e de transformá-la.

\footnotetext{
A leitura do mundo precede a leitura da palavra, daí que a posterior leitura desta não possa prescindir da continuidade da leitura daquele. Linguagem e realidade se prendem dinamicamente. A compreensão do texto a ser alcançada por sua leitura crítica implica a percepção das relações entre o texto e o contexto (FREIRE, 1982, p. 9).
}

É nesse ato dinâmico presente entre linguagem e realidade que se encontra a capacidade de se ler o mundo, de modo que a pessoa, mesmo não alfabetizada no mundo das letras, é capaz de identificar e reconhecer diferentes linguagens.

Saber decodificar os signos linguísticos e interpretar o texto também requerem um olhar diferenciado por parte dos profissionais da educação, quando se trata de aprendizes da EJA que trazem saberes, como por exemplo reconhecer os rótulos de produtos, devido ao conhecimento que adquiriram, apesar de não terem frequentado espaços formais de ensino.

De acordo com Kuenzer:

Leitura, escrita e fala não são tarefas escolares que se esgotam em si mesmas; que terminam com a nota bimestral. Leitura, escrita e fala - repetindo - são atividades sociais, entre sujeitos históricos, realizadas sob condições concretas (KUENZER, 2002, p. 101).

Concorda-se com Kuenzer (2002), no sentido de que as práticas de leitura e escrita tendem a contribuir com a formação de sujeitos autônomos, atuantes no contexto, de modo que os estudantes tenham condições a identificar problemas, debater de forma coletiva e a se posicionar linguisticamente e discursivamente em situações, sejam elas do seu cotidiano ou do contexto mais amplo.

Revista Expectativa, Toledo/PR, v. 20, n. 2, p. 164-182, abr./jun., 2021. 


\subsection{A EDUCAÇÃO PERMANENTE}

No contexto atual, marcado pela necessidade de renovação constante dos conhecimentos e das habilidades, vale questionar: Até quando convém a educação do sujeito? Se for considerado que a finalidade educativa estiver centrada no processo de formação integral do sujeito e de sua humanização, bem como na integração e transformação social, há que se pensar num processo educativo para a vida toda. Nesse caso, vislumbra-se uma educação permanente que se prolonga durante todo o ciclo vital do ser humano, sendo condição o aprendizado de forma constante (SCHMIDT, 2011).

Uma das premissas do projeto de educação para toda a vida centra-se, portanto, na necessidade de a pessoa sempre aprender. Isso corresponde, conforme a perspectiva ontológica do ser humano, à existência humana que surge com a esperança de um desenvolvimento contínuo, ao longo de toda a vida.

Conforme Palma e Cachioni (2006), a educação permanente se traduz numa tarefa, num direito, assim como é um dever ao longo da vida. Sempre existe a possibilidade, independentemente da idade cronológica ou da época, de se almejar uma educação que não se conclui, visto que o ser humano é um projeto inacabado. Para essas autoras, a educação permanente "é um princípio no qual se fundamenta a organização global de um sistema" (PALMA; CHACHIONI, 2006, p. 1104).

A importância de um processo educacional continuado, segundo Oliveira (1999), inscreve-se no inacabamento do sujeito, visto que, diferentemente de outras espécies, o ser humano nasce prematuro física e psiquicamente, implicando um constante processo de construção, de aprendizagem, até seu último suspiro. "A educação tem caráter permanente. A educação é possível para o homem, porque este é inacabado e sabe-se inacabado" (FREIRE, 1983, p. 28).

Segundo Palma e Cachioni, o aprendizado contínuo

[...] é uma exigência nova, de autonomia dinâmica dos indivíduos numa sociedade em constante transformação. [...] as pessoas adultas e idosas precisam recorrer, constantemente, aos seus conhecimentos e capacidades de discernimento para poderem orientar-se, pensar e agir (PALMA; CACHIONI, 2006, p. 1102). 
Pautado no relatório de Delors (1999), sob o título Educação - Um Tesouro a Descobrir, a educação é uma construção contínua da pessoa humana, para toda a sua vida e deve ser um instrumento de conscientização do ser humano e do meio, assim como auxiliá-lo a desempenhar o papel social que lhe cabe no mundo do trabalho e na comunidade.

Nesse mesmo texto, constam os quatro pilares do conhecimento para o século XXI, a saber: aprender a conhecer, aprender a fazer, aprender a viver juntos e aprender a ser (DELORS, 1999, p. 90), princípios que se aplicam na educação, tanto na esfera formal, como na não-formal.

Reitera-se a importância desses pilares, entretanto, depreende-se que aprender a viver juntos e aprender a ser devam ser foco no contexto da Educação de Jovens e Adultos, visto que desenvolvem a percepção de interdependência dos indivíduos, auxilia a administrar conflitos, a participar de projetos comuns, com o intuito da realização plena da pessoa, ou seja, "o desenvolvimento total da pessoa - espírito e corpo, inteligência, sensibilidade, sentido estético, responsabilidade pessoal, espiritualidade (DELORS, 1999, p. 101)”.

Dessa forma, a educação permanente tem uma relação muito importante com a EJA, principalmente quando se refere às pessoas com mais idade, que estão inseridas neste contexto, pois é pelo convívio com outros indivíduos que os sujeitos aprendem continuamente e desenvolvem novas habilidades. A educação permanente não atua somente no âmbito escolar, mas alcança outros espaços sociais, os quais contribuem para o pleno desenvolvimento e a contínua interação dessas pessoas.

\subsubsection{A Educação de Jovens e Adultos e Propostas Curriculares}

A Educação de Jovens e Adultos (EJA) é um direito assegurado pela lei de Diretrizes e Bases da Educação Nacional (BRASIL, 1996), a qual é ofertada gratuitamente aos que não tiveram acesso na idade própria e segundo esse documento, o poder público deverá incentivar o acesso e a permanência dos jovens e dos adultos na escola.

Mediante essa realidade sociopolítica e educacional, pode-se abordar um pouco sobre a trajetória da EJA no Brasil, e sua contribuição para a população brasileira.

A Alfabetização de Jovens e Adultos não é algo recente, se deu início desde a colonização, mas só foi reconhecida oficialmente após o ano de 1945. Vale destacar que são 
inúmeros os motivos que interferem no processo de alfabetização na idade regular de alguns jovens e adultos, sendo que alguns nem chegaram a iniciar a escolarização em uma instituição, mas nos dias atuais sentem a necessidade de aprender a ler e a escrever. Segundo Moll:

\begin{abstract}
Nesse sentido, quando falamos 'em adultos em processo de alfabetização' no contexto social brasileiro, nos referimos a homens e mulheres marcados por experiências de infância na qual não puderam permanecer na escola pela necessidade de trabalhar, por concepções que as afastavam da escola como de que 'mulher não precisa aprender' ou 'saber os rudimentos da escrita já é suficiente', ou ainda, pela seletividade construída internamente na rede escolar que produz ainda hoje itinerários descontínuos de aprendizagens formais. Referimo-nos a homens e mulheres que viveram e vivem situações limite nas quais os tempos de infância foi, via de regra, tempo de trabalho e de sustento das famílias (MOLL, 2004, p. 11).
\end{abstract}

Nesse sentido, entre a infinidade de funções atribuídas a essa modalidade de ensino, baseados no Currículo do município de Cascavel/PR, compreende-se o papel da EJA como o de fornecer subsídios para que os educandos se afirmem como sujeitos ativos, críticos, criativos e democráticos, bem como colaborar para que eles ampliem seus conhecimentos de forma crítica, viabilizando a reflexão pela busca dos direitos de melhoria de sua qualidade de vida (CASCAVEL, 2008).

Já, em âmbito estadual, as Diretrizes Curriculares para essa modalidade de ensino, advogam que a escola representa um dos espaços favoráveis à formação de sujeitos críticos. “A educação de jovens e adultos tem um papel fundamental na socialização dos sujeitos, agregando elementos e valores que os levam à emancipação da sua identidade cultural" (PARANÁ, 2008, p. 29).

Tanto a leitura quanto a escrita desempenham papel fundamental e diversas finalidades na vida dos sujeitos e perpassam diversos espaços e situações sociocomunicacionais, seja na escola, no lazer, no trabalho ou até mesmo em casa. Cagliari diz que: "A escola deve acompanhar a evolução do mundo, mas ela também é uma guardiã da tradição. Do equilíbrio entre as duas coisas nasce a verdadeira formação que deve dar a seus alunos" (CAGLIARI, 2008, p. 174-175).

Dessa forma, reafirma-se a importância de os sujeitos estarem inseridos em contextos formais de ensino, nos quais oportunizam-se o contato e a interação com diversas linguagens, textos, culturas e tecnologias. Isso, no entanto, não implica que:

Revista Expectativa, Toledo/PR, v. 20, n. 2, p. 164-182, abr./jun., 2021. 
Muitos destes processos se desenvolvem de modo mais ou menos sistemático fora de ambientes escolares, realizando-se na família, nos locais de trabalho, nos espaços de convívio socioculturais e lazer, nas instituições religiosas e, nos dias atuais, também com o concurso dos meios de informação e comunicação à distância (HADDAD; DI PIERRO, 2000, p. 4).

Não basta apenas saber ler e escrever os códigos, mas sim decodificar esses códigos e transcrevê-los, para assim poder compreender e se apropriar daquilo que foi escrito. Vale refletir acerca de quais seriam as mediações adequadas, tratando-se da modalidade da EJA, além de como conciliar o conhecimento prévio ao que será construído.

Sendo assim, nessa modalidade de ensino, requer que o professor considere em sua prática pedagógica, questões como: (i) $\mathrm{O}$ que os alunos entendem por leitura e escrita?; (ii) O eles que acham que podem conseguir por meio dessas habilidades?; (iii) Qual a importância da leitura e da escrita para esses sujeitos?

No âmbito do trabalho educativo formal com jovens, adultos e, até idosos, as coisas do mundo possuem significações adquiridas das experiências existenciais de cada indivíduo, portanto, deve estar presente no contexto de formação e aplicações de aulas nessa modalidade de ensino.

É o que justamente advogam Gadotti e Romão (2001), ao abordarem que as práticas pedagógicas para com os alunos da EJA devem ter o cuidado de não serem reprodutoras do ensino regular, nem tampouco serem facilitadoras do processo de ensino e aprendizagem. Mas nas palavras dos autores, elas devem orientar-se "na perspectiva epistemológica que toma o jovem e o adulto como construtores de conhecimento, interagindo com a natureza e o mundo social, tendo como ponto fundamental o respeito à cultura dos sujeitos" (GADOTTI; ROMÃO, 2001, p. 123).

Quando se tematiza a leitura e escrita não se percebe a importância que ambas desempenham na vida de quem não é alfabetizado, nem letrado. A falta de proficiência com relação às habilidades da leitura e da escrita podem acarretar ao indivíduo um leque de sentimentos e impossibilidades, tais como: tristeza, vergonha, dependência, entre outros.

Ao mesmo tempo, diversos são os fatores que instigam jovens, adultos e, até mesmo idosos, a buscarem sua inserção nas instituições de ensino, sendo a aceitação pessoal e familiar, a aceitação por parte da sociedade, bem como a necessidade exigida pelo mercado de trabalho que, às vezes, se torna uma necessidade preconceituosa e excludente, os mais recorrentes.

Revista Expectativa, Toledo/PR, v. 20, n. 2, p. 164-182, abr./jun., 2021. 
Por esses e tantos outros motivos, muitas pessoas são levadas a frequentar a modalidade da Educação de Jovens e Adultos, já que o acesso à leitura e à escrita pode agregar a esses aprendizes diversos benefícios e resultados positivos. É preciso também que os educandos tenham noção da importância da leitura e da escrita em seu cotidiano, analisando situações onde se evidencie a necessidade do ato de ler e escrever; enfim, que adquiram significados práticos na vida dos alunos e que sejam alcançados e conciliados com suas necessidades e interesses básicos.

\section{PROCEDIMENTOS METODOLÓGICOS}

Segundo Gil (1999), pesquisa é definida como o procedimento racional e sistemático que tem como objetivo proporcionar respostas aos problemas que são propostos. A investigação desenvolve-se por um processo constituído de várias fases, desde a formulação do problema até a apresentação e discussão dos resultados.

Nesse percurso metodológico destaca-se, também, a etapa do estudo bibliográfico, que conforme Fonseca "permite ao pesquisador conhecer o que já se estudou sobre o assunto" (FONSECA, 2002, p. 32). Para esse autor, essa fase depreende de um levantamento de referências e pesquisas que já estejam publicadas nos meios escritos e eletrônicos, desde os livros, artigos científicos, até as páginas de websites.

Especificamente neste estudo utilizou-se da abordagem qualitativa, uma vez que o processo de construção do conhecimento científico caracteriza-se pela relação estabelecida entre o sujeito e o objeto, podendo-se dizer que esta é uma relação de reconhecimento e de apropriação. Sobre a pesquisa qualitativa Jesus e Domingues, inferem que ela "envolve a obtenção de dados descritivos, obtidos no contato direto do pesquisador com a situação estudada, enfatiza mais o processo do que o produto [...]" (JESUS; DOMINGUES, 1999/2000, p. 117).

Outro aspecto a ser considerado neste estudo diz respeito ao objeto central caracterizarse num único espaço educativo formal, isto é, um estudo de caso propriamente dito. No entendimento de André: “O conhecimento gerado pelo estudo de caso é diferente do de outros tipos de pesquisa porque é mais concreto, mais contextualizado e mais voltado para a interpretação do leitor" (ANDRÉ, 2013, p. 97).

Revista Expectativa, Toledo/PR, v. 20, n. 2, p. 164-182, abr./jun., 2021. 
Ainda Lüdke e André:

[...] a questão de escolher, por exemplo, uma escola comum da rede pública ou uma escola que esteja desenvolvendo um trabalho especial dependerá do tema de interesse, o que vai determinar se é um tipo de escola ou em outro que a sua manifestação se dará de forma mais completa, mais rica e mais natural (LÜDKE; ANDRÉ, 2004, p. 23).

Sendo assim, o trabalho tem como base a pesquisa realizada na Escola Municipal Francisco Vaz de Lima que oferece a modalidade da Educação de Jovens e Adultos na rede municipal de Cascavel, no Estado do Paraná. De forma geral, essa escola comporta 936 alunos, que frequentam a Educação Infantil e o Ensino Fundamental, assim como conta com 41 professores, 27 servidores (zeladores, cozinheiras e parte administrativa) e também sete estagiários.

A Educação de Jovens e Adultos está presente nesta instituição desde 2006, ano em que houve a descentralização do Centro de Ensino Paulo Freire em Cascavel. A escola possui uma turma de EJA, formada por 21 alunos, sendo que as aulas são no período noturno.

Em relação aos procedimentos metodológicos, destaca-se que nesse espaço educativo foram coletados alguns dados, obtidos mediante a aplicação do questionário intitulado 'Práticas de leitura e escrita na Educação de Jovens e Adultos' com questões pré-estabelecidas estendidas aos estudantes que estavam presentes em sala (aos que se dispuseram a responder o mesmo).

Para Gil, questionário pode ser definido

[...] como a técnica de investigação composta por um número mais ou menos elevado de questões apresentadas por escrito às pessoas, tendo por objetivo o conhecimento de opiniões, crenças, sentimentos, interesses, expectativas, situações vivenciadas etc (GIL,1999, p. 128).

A aplicação desse instrumento investigativo sucedeu-se de forma anônima, e apresenta sete questões sobre a presente temática. Essa ação de 'estudar o caso', mediante contato direto com a turma e o professor da EJA ocorreu no mês de setembro.

O referido questionário está composto por perguntas relacionadas à leitura, escrita e à importância das mesmas em sua formação escolar, como também em suas vidas cotidianas, e se tal aprendizado é relevante para os alunos da EJA.

Nesse sentido, na data da aplicação do questionário, foram inicialmente solicitados que os participantes informassem sua idade e o tempo de inserção na Educação de Jovens e Adultos.

Revista Expectativa, Toledo/PR, v. 20, n. 2, p. 164-182, abr./jun., 2021. 
Também foram feitas seis questões visando compreender a importância (ou não) das práticas da leitura e da escrita na formação desses alunos.

O professor que estava presente em sala no momento da aplicação do mesmo, foi quem garantiu o suporte necessário para que os alunos pudessem responder o que lhes foi pedido em primeiro momento, pois parte da turma está em processo de alfabetização, e por este motivo a leitura e a explicação do professor referente ao questionário foi fundamental naquela hora. Vale destacar que foi necessário ir até a instituição de ensino uma segunda vez, pois a primeira questão que trata da idade e tempo de inserção dos mesmos nesta modalidade de ensino não foi respondida pela maioria.

Além disso, visando a coleta de dados e a posterior compreensão e análise sobre o fenômeno - a relevância do processo do aprendizado da leitura e a escrita por parte dos alunos e dos métodos utilizados pelo professor, reitera-se que a turma em questão foi observada em sala de aula em distintos momentos.

É o que enfatiza Gil (1987) sobre a técnica do estudo de caso, o qual compreende alguns passos, quer sejam: (i) explorar situações da vida real cujos limites não estão claramente definidos; (ii) preservar o caráter unitário do objeto estudado; (iii) descrever a situação do contexto em que está sendo feita determinada investigação; (iv) formular hipóteses ou desenvolver teorias; e (v) explicar as variáveis causais de determinado fenômeno em situações muito complexas que não possibilitam a utilização de levantamentos e experimentos.

\section{DISCUSSÃO E ANÁLISE DOS RESULTADOS: APROXIMAÇÕES ENTRE AS PRÁTICAS DE LEITURA E ESCRITA NA FORMAÇÃO DE JOVENS E ADULTOS}

Com base nas informações destacadas acima e buscando sanar os questionamentos levantados, seguem uma descrição e uma análise acerca do questionário entregue aos alunos participantes, bem como de suas respostas, a fim de compreender qual o entendimento desses sujeitos sobre o papel da leitura e da escrita em suas vidas e na sua trajetória escolar.

Vale salientar que o questionário foi respondido por nove alunos, e como foi citado na seção anterior, a primeira questão constante no questionário não foi respondida pela maioria deles. Sendo assim, a volta à escola foi necessária para averiguar sobre tais informações; e esta 
questão foi respondida com a ajuda de uma funcionária da escola que, por ser secretária da instituição, tem acesso às listas com a idade dos alunos.

A partir desses contatos, obteve-se a informação sobre a idade dos participantes que se dispõe entre 27 a 72 anos, ou seja, pessoas com idades cronológicas muito distintas. A conversa com a funcionária da escola foi oportuna, pois resultou num encontro informal, com relatos desta funcionária, que por sua vez tem interação com alguns dos alunos. Essa informante relatou que há uma variedade de motivos para os alunos estarem frequentando a EJA, dentre eles estão: necessidade de emprego, convivência com outras pessoas que não sejam de sua própria família, a busca por um maior entendimento sobre assuntos que lhes são pertinentes e etc.

Além disso, entre as informações que merecem destaque, consta o relato que a mesma funcionária fez sobre uma das alunas, que pelo fato de conhecê-la em contexto extraescolar, sabe que a aluna, apesar de não conseguir aprender mais, por dificuldades de audição e visão, ainda continua frequentando esta turma apenas para manter o diálogo com outras pessoas.

Essa informação corresponde com a perspectiva da educação permanente, ou seja, o fato de que frequentar os espaços formais de ensino em idade avançada não diz respeito apenas ao acesso aos conhecimentos sistematizados, e sim o aprendizado pela vida toda adquire um papel relevante na vida de algumas pessoas. No que diz respeito ao tempo de inserção na EJA, isso difere, pois cada uma desses alunos busca uma finalidade particular ao se inserir na modalidade de ensino.

Em relação às questões específicas sobre a leitura e a escrita presentes no questionário, consta a pergunta sobre a importância e o significado dessas práticas na vida dos alunos, já que o intuito é compreender se de fato são (ou não) importantes.

Diante disso, de forma unânime houve retorno positivo, uma vez que todos afirmaram serem essas práticas muito importantes para as suas vidas, no caso os próprios alunos, sujeitos participantes $^{3}$ deste estudo, infeririam positivamente.

Especificamente, na segunda parte desta questão o Aluno 4 e o Aluno 8 disseram com suas palavras que: "sem a leitura e a escrita não sou ninguém", o que demonstra o grau de importância que eles atribuem a ambas. Já o Aluno 3 e o Aluno 9 destacaram a importância da leitura e da escrita como condição para conseguirem vínculo empregatício.

\footnotetext{
${ }^{3}$ Para fins de preservação do anonimato dos nove participantes, optou-se em identificá-los por Aluno 1, Aluno 2 e, assim, sucessivamente.
}

Revista Expectativa, Toledo/PR, v. 20, n. 2, p. 164-182, abr./jun., 2021. 
Nesses relatos pode-se verificar que, conforme Palma e Cachioni (2006), a renovação dos conhecimentos se trata de uma necessidade atual em função da sociedade eminentemente dinâmica, mutável e diversa. Para essas autoras, "as pessoas adultas e idosas precisam recorrer, constantemente, aos seus conhecimentos e capacidades de discernimento para poderem orientar-se, pensar e agir (PALMA; CACHIONI, 2006, p. 1102)". Tais competências são, dessa forma, essenciais para garantir a autonomia desses sujeitos na sociedade contemporânea e complexa.

O Aluno 5 destaca que pode ler tudo o que for de seu agrado; já, o Aluno 7 informa que é importante "por que eu consigo me comunicar com as outras pessoas e entender melhor o mundo", fato esse que chama a atenção, pois é através das interações sociais que os sujeitos se desenvolvem e entendem melhor o mundo. Ainda o Aluno 1 e o Aluno 6 reiteram o fato delas serem importantes; porém o Aluno 2, apesar de destacar a sua alegria em estudar e ler os textos, considera a sua própria leitura muito fraca.

Quanto à pergunta seguinte que versa acerca do interesse dos alunos pela leitura e a escrita, e se isso tem alguma relação com o fato deles estarem cursando a EJA, as respostas dos questionários demonstram que são positivas. Sendo que os participantes reforçam o significado valorativo das práticas de leitura e escrita e reafirmam o fato de que elas despertaram o interesse dos alunos no momento da inserção na EJA.

Especificamente o Aluno 1 e o Aluno 6 comentam sobre a felicidade que sentem por estarem inseridos na EJA, por aprenderem cada dia mais, e isso demonstra a satisfação dos mesmos. Já o restante dos alunos, mediante uso de palavras diferentes, diz que a leitura os influencia a buscar cada vez mais o aprendizado. Pode-se depreender dos relatos feitos que esse dado é relevante, pois a vontade de aprender é um grande passo para que consigam alcançar o que desejam.

$\mathrm{Na}$ pergunta seguinte os participantes foram questionados sobre o fato de retornarem aos estudos ter influenciado um maior uso da leitura e da escrita em seus cotidianos. Sobre essa proposição, os alunos confirmaram haver mais frequência e mais uso da leitura no cotidiano, sendo que dos nove participantes questionados, sete inferiram que a leitura e a escrita se tornaram mais presentes em suas vidas e que as praticam rotineiramente. Isso corresponde com o entendimento de Soares (2001), ao inferir que a noção de letramento transcende a questão do ato de ler e de escrever, pois refere-se aos usos sociais da leitura e da escrita. 
Já os Alunos 7 e 9, apesar de terem concordado com o maior uso da leitura e escrita após o contato com a EJA, dizem que isso ocorre em sala de aula, e pelo fato de fazer parte da sua rotina escolar. O entendimento dos aprendizes reforça o que, para Freire (1982), reflete a leitura crítica do mundo e a percepção das relações textuais e contextuais.

No que diz respeito às dificuldades em relação à leitura e à escrita na escola, lhes foi solicitado no questionário que, se houvessem tais dificuldades, os participantes as identificassem. Ainda, nessa mesma questão, solicitou-se que os alunos informassem se e como essas dificuldades foram superadas. Quanto ao retorno dessa questão, todos os respondentes, de certa forma, inferiram que existem dificuldades.

De uma parte, as dificuldades podem ser concebidas como normais em todos os níveis e modalidades de ensino; já de outra parte, entende-se que seja necessária uma prática de leitura e escrita constante para que possam ser superadas as barreiras que surgem.

Retomando os relatos dos alunos, a maioria manifestou ter algum tipo de dificuldade, com exceção do Aluno 1 que destacou ser a leitura uma surpresa para ele, mas não identifica as suas dificuldades para com o processo da leitura. Já os demais participantes explicitaram suas dificuldades em relação à leitura de textos, o que, segundo os informantes, ocorre pelo fato de não conseguirem fazer a interpretação imediata dos textos. Ao mesmo tempo os alunos enfatizaram que quando isso acontece, os mesmos leem "quantas vezes forem necessárias" para que compreendam os textos aplicados em sala.

Na pergunta posterior, procurou-se verificar se na opinião dos participantes, o contato e a leitura com diversos tipos de textos na escola contribuem para a formação e interação social deles e em que medida isso ocorre. Também nessa questão os posicionamentos dos participantes foram convergentes, uma vez que os nove alunos concordaram em manifestar que o contato com diferentes gêneros textuais contribui para a formação e interação social deles.

Entre os registros que comprovam essas opiniões, constam o relato do Aluno 3 ao inferir que "Sim, contribui, a leitura me faz eu ter uma visão diferente das coisas onde eu posso participar do meio social". Também o Aluno 7 quando afirma que "Ajuda e muito. Quanto mais eu leio mais eu entendo o que está acontecendo com a sociedade. A leitura me faz pensar diferente”. Ainda a colocação do Aluno 9: “Ah sim, contribui fazendo sim eu ler diversas coisas e eu participar da sociedade”.

Revista Expectativa, Toledo/PR, v. 20, n. 2, p. 164-182, abr./jun., 2021. 
Nesse sentido, os alunos concordaram em manifestar que este contato com diferentes gêneros textuais contribui significativamente para sua formação e sua interação com os demais sujeitos. Depreende-se que essa visão seja significativa, pois auxilia-os a ocuparem seu espaço no contexto do trabalho e na comunidade (DELORS, 1999); assim como as práticas de leitura e escrita contribuem com a formação da autonomia de cidadãos, com vistas a atuarem de forma proativa no contexto social (KUENZER, 2002).

O uso da língua na modalidade oral e escrita é de suma importância para que os sujeitos tenham condições de interagir, de forma proficiente, nos diversos contextos linguísticos e socioculturais. No entendimento dos Parâmetros Curriculares Nacionais mediante esse conhecimento linguístico o sujeito "comunica, tem acesso à informação, expressa e defende pontos de vista, partilha ou constrói visões de mundo, produz conhecimento" (BRASIL, 2001, p. 15). Nesse sentido, independentemente da idade cronológica que determinada pessoa tenha, é possível pensar numa formação constante e permanente do sujeito crítico.

É o que reafirma Antunes (2010), ao destacar que o processo da leitura e da escrita são processos eminentemente interativos, por isso não tem sentido escrever quando não se está procurando agir com o outro, trocar ideias, informações, sob algum pretexto. Logo, são atividades contextualizadas em determinados momentos, espaços e eventos socioculturais.

Por fim, foi inquerido que os participantes informassem se haviam sofrido alguma exclusão social pelos seus conhecimentos em relação à leitura e à produção de texto e que descrevessem essa situação.

Vale destacar que entre os nove alunos, um não respondeu a este questionamento, sendo que os demais enfatizaram que já haviam sofrido algum tipo de exclusão social pelo fato de não saberem ler ou escrever. Os Alunos 3, 7, 8 e 9 descrevem o fato de que, quando foram em busca de emprego, haviam ficado envergonhados, pois não conseguiam responder formulário, ou até mesmo o próprio nome quando lhes fora solicitado. Já os alunos 1, 5 e 6 relatam o fato de que tinham muitas dificuldades e achavam que não conseguiriam aprender, mas que na atualidade estão inseridos na EJA e que aprendem a cada dia mais e, por isso, estão mais felizes. 


\section{CONSIDERAÇÕES FINAIS}

Por um lado, ao retomar as questões centrais deste estudo, considera-se os limites de um estudo de caso ao procurar compreender qual a relevância da leitura e da escrita para os jovens, adultos e idosos inseridos nessa modalidade de ensino.

Por outro lado, reconhece-se as contribuições desta pesquisa, ao atestar como elemento recorrente, o papel valorativo e significativo dessas práticas no tocante às vidas dos participantes desse estudo, bem como ao mensurar o quanto a leitura tem influenciado os alunos, participantes deste estudo, a ingressarem na modalidade da EJA.

Para tanto, depreende-se que a leitura e a escrita, apesar de representarem desafios de ordem interpretativista aos alunos, continuam sendo uma possibilidade a novos conhecimentos, trazendo benefícios linguísticos, cognitivos e psicossociais. Finalmente, a Educação de Jovens e Adultos tem o papel de ampliar o letramento de seus alunos, para que estes possam desenvolver capacidades de leitura e escrita em diversos contextos sociais, com vistas à participação ativa e autônoma na sociedade.

\section{REFERÊNCIAS}

ANDRÉ, Marli. O que é um Estudo de Caso qualitativo em Educação? Revista da FAEEBA - Educação e Contemporaneidade, Salvador, v. 22, n. 40, jul./dez., p. 95-103, 2013.

ANTUNES, Irandé. Análise de Textos: fundamentos e práticas. São Paulo: Parábola, 2010.

BRASIL, Secretaria de Educação Fundamental. Parâmetros Curriculares Nacionais: Língua Portuguesa. Brasília: Secretaria de Educação Fundamental, 2001.

CAGLIARI, Luiz Carlos. Alfabetização e Linguística: pensamento e ação no magistério. Editora Scipione, 2008.

CASCAVEL. Secretaria Municipal de Educação. Currículo para Rede Pública Municipal de Ensino de Cascavel Educação de Jovens e Adultos - Ensino Fundamental fase I. Cascavel, PR: Ed. Progressiva, 2008, v. III. 236p.

DELORS, Jacques. Educação: um tesouro a descobrir. Relatório da Comissão Internacional sobre Educação para o Século XXI. São Paulo: Cortez, 1999.

FREIRE, Paulo. Educação e Mudança. 13. ed. Rio de Janeiro: Paz e Terra, 1983. 
FREIRE, Paulo. A importância do ato de ler: em três artigos que se complementam. 23. Ed. São Paulo: Cortez, 1982.

FONSECA, J. J. S. Metodologia da pesquisa científica. Fortaleza: UEC, 2002. Apostila.

FERREIRA, Verena Santos Andrade. A Leitura na Educação de Jovens e Adultos: experiências e representações. 2012. Disponível em: http://www.ppgel.uneb.br/wp/wpcontent/uploads/2012/04/ferreira_verena.pdf. Acesso em: 30 jul. 2019.

GIL, A. C. Métodos e técnicas de pesquisa social. 5. ed. São Paulo: Atlas, 1999.

GADOTTI, Moacir; ROMÃO José E. Diretrizes Nacionais. In: GADOTTI, Moacir; ROMÃO José E. (Org). Educação de jovens e adultos: teoria, prática e proposta. São Paulo: Cortez: Instituto Paulo Freire, p. 119-129, 2001.

HADDAD, Sérgio; DI PIERRO, Maria Clara. Escolarização de jovens e adultos. Revista Brasileira de Educação, Rio de Janeiro, n. 14, p. 108-130, 2000.

JESUS, Renildo n. Machado de; DOMINGUES, Sandra. Revista Científica em Educação, Unisul, v.1/2, n.2/3, p.113-117, jul/jun. 1999/2000.

KLEIMAN, Ângela B. Modelos de Letramento e as Práticas de Alfabetização na Escola. In: KLEIMAN, Ângela. Os significados do letramento: uma nova perspectiva sobre a prática social da escrita. Campinas: Mercado das Letras, 1995.

KUENZER, Acácia. Ensino Médio: Construindo uma proposta para os que vivem do trabalho. 3. ed., SP: Editora Cortez, 2002.

LÜDKE, Menga; ANDRÉ, Marli E. Dalmazo Afonso de. Pesquisa em Educação: abordagens qualitativas. São Paulo: E.P.U. 2004.

MOLL, Jaqueline. Alfabetização de adultos: desafios à razão e ao encantamento. In: MOLL, Jaqueline (Org). Educação de jovens e adultos. Porto Alegre: Mediação, p. 9-18, 2004.

PARANÁ. Diretrizes Curriculares Nacionais para a Educação Básica, 2008.

PALMA, Lúcia S.; CACHIONI, Meire. Educação permanente: perspectiva para o trabalho educacional com o adulto maduro e com o idoso. In: FREITAS, Elizabete V. et al. Tratado de Geriatria e Gerontologia. Rio de Janeiro: Guanabara Koogan, p.1101-1109, 2006.

SCHMIDT, Cristiane. Identidade de idosos aprendizes de língua estrangeira: algumas considerações. Educere et Educare, v.6, p. 243 - 254, 2011.

SILVA, Ezequiel Theodoro. Concepções de leitura e suas consequências no ensino. Perspectiva. Florianópolis, v. 17, n. 31, p. 11-19, 1999.

SOARES, Magda. Letramento: um tema em três gêneros. 2. ed., Belo Horizonte: Editora Autêntica, 2001. 
A relevância das práticas de leitura e escrita na formação do sujeito inserido na educação de jovens e adultos: um estudo de caso

SOARES, Magda. Alfabetização e letramento. $2^{\text {a }}$. ed., São Paulo: Editora Contexto, 2003a.

SOARES, Magda. Alfabetização: a ressignificação do conceito. 2003. Alfabetização e Cidadania, n. 16, p. 9-17, 2003 b.

STREET, Brian. Letramento em teoria e prática. Trad. Marcos Bagno, Cambridge: Cambridge University Press, 1984. 